\title{
Single Exponential Smoothing Method to Predict Sales Multiple Products
}

\author{
Rendra Gustriansyah ${ }^{1, *}$
}

\begin{abstract}
Activity to predict sales multiple products intended for control of the number of existing stock, so the lack or excess stock can be minimized. When the number of sales can be accurately predicted, then the fulfilment of consumer demand can be cultivated in a timely and cooperation with suppliers maintained properly so that company can avoid losing sales and customers. This study aims to predict sales multiple products (6,877 products) using Single Exponential Smoothing (SES) approach, which is expected to improve the efficiency of the inventory system. Measurement accuracy of prediction in this study using a standard measurement Mean Absolute Percentage Error (MAPE), which is the most important criteria in analyzing the accuracy of the prediction. The results showed that the average of percentage prediction error of products using SES is high, because MAPE value obtained is $1.056 \%$ with a smoothing parameter $\alpha=0.9$.
\end{abstract}

Keywords-Single Exponential Smoothing, Sales Prediction, MultiProducts, MAPE.

\section{INTRODUCTION}

$\mathbf{P}$ redicting the sales quantity is an activity to estimate the number of product sales by a manufacturer or distributor for a specific time period and area marketing. Predicting sales is also part of the management functions as one of the contributors to a company's success. Because the failure of the company to provide such products can have negative implications on the level of service to consumers so that it will reduce the competitiveness of the company. As a result, corporate profits will be reduced, because the consumer will choose a company that can meet their needs.

Actually, activity to predict the sales quantity is not a simple forecasting or replenishment, but the management and scientific control and effective to improve the company management and market penetration capacity, optimization of customer service fast and coordinated as well as economic benefits to the company [1].

Predicting the sales quantity in the future is to control the amount of the stock of existing products, in order lack or excess of stock products can be minimized. When the number of sales can be accurately predicted, then the fulfillment of consumer demand can be cultivated on time, and cooperation with suppliers maintained properly so that the company can overcome the loss of sales or out of stock, and prevent consumers 'run' to competitors.

Predicting the sales quantity that are too large or less accurately may also lead to increased costs associated with inventory so that investment becomes inefficient [1], especially if many products will be predicted.

${ }^{1}$ Department of Informatics Engineering, Faculty of Computer Science Universitas Indo Global Mandiri, Jalan Jenderal Sudirman No. 629, Palembang Indonesia.

*Correspondence to T. Author, email: rendra@uigm.ac.id. Tel.:+62-711322705; fax.:+62-711-357758.

\section{A. Single Exponential Smoothing}

Exponential smoothing method was first suggested in the statistical literature by Robert Goodell Brown in 1956, and then expanded by Charles C. Holt in 1957. In its simplest form that known as single exponential smoothing (SES).

SES method including quantitative prediction methods with historical data patterns is unstable and based on time series. The exponential term in this method is derived from weighting (smoothing parameter from prior periods that shaped exponential) [11].

SES method is a procedure that continuously improve the prediction by averaging past values of a time series data by way of decreasing (exponential) [11].

Characteristics of this method is the analyzed data are time series and appropriate for a horizontal pattern, as well as using different parameters for past data, where the parameter decreases exponentially from the value of the most recent observations up to the longest observed values.

SES method is more suitable for predicting fluctuations things randomly (irregularly). SES method can be described mathematically as follows [11]:

$$
\mathrm{F}_{\mathrm{t}}=\mathrm{F}_{\mathrm{t}-1}+\alpha\left(\mathrm{A}_{\mathrm{t}-1}-\mathrm{F}_{\mathrm{t}-1)}=\alpha \mathrm{A}_{\mathrm{t}-1}+(1-\alpha) \mathrm{F}_{\mathrm{t}-1},\right.
$$

where $F_{t}$ is the new predictive value in period $t, F_{t-1}$ is the predictive value for the period $t-1$ (previous), $A_{t-1}$ is the actual value for the period $t-1$, and $\alpha$ is the smoothing parameter $(0$ $\leq \alpha \leq 1)$.

The term of smoothing parameter applied to $\alpha$ is something of a misnomer, as larger values of $\alpha$ actually reduce the level of smoothing, and in the limiting case with $\alpha=1$, the output series is just the same as the original series (with lag of one time unit). Smoothing refers to the averaging that takes place when we calculate a weighted average of the past data.

\section{Materials AND MethodS}

\section{A. Data Collection}

The collection of data is the most important stage in the research. Data collection in this study is time series data, namely data collected within a certain time based on the time at equal intervals (every month) to describe the development of an activity, such as product development, sales, and price.

The data used in this study were imported from the database of a pharmacy in Palembang city, consisting of a table of products (6,877 items), tables of sales transactions and detailed sales from January to December 2015 (399,738 records) [2].

\section{B. Data Analysis}

Analysis of time series data is a statistical procedure on time series data are applied to predict the state will come into 
the decision making process. Time series data are usually analyzed to find patterns of growth or changes in the past that can be used to predict future patterns in line with the needs of business operations.

Time series data in this study is a summary of all the sales transaction data and details of any pharmaceutical product sales from January to December are showing a graph with horizontal data pattern as shown in Fig. 1.



Fig. 1. A graph each product quantity sales per month.

Fig. 1 shows that the graph of the pattern of data quantity every pharmaceutical product sales from January to December was relatively linier and has a rising trend (exponential), so that the exponential smoothing method can be applied to the data pattern like this.

\section{Measurement Error Prediction}

In fact, there is no prediction has an accuracy rate of $100 \%$, because every prediction certainly contain errors. Therefore, to determine the prediction method that has a high degree of accuracy, it is necessary to calculate the error rate in the prediction. The smaller of error margin is generated, the better the prediction method. Calculation of the prediction error is also the calculation accuracy in the measurement.

The general standard of measurement used prediction error is the mean absolute error (MAE) for accuracy, and the mean absolute percentage error (MAPE) to the percentage of accuracy [11], [12].

1) Mean Absolute Error (MAE):

$$
M A E=\frac{1}{n} \sum_{t=1}^{n}\left|A_{t}-F_{t}\right|
$$

where $A_{t}$ is the actual value at the time to $t, F_{t}$ is the predicted value at time to $\mathrm{t}$, and $\mathrm{n}$ is lots of data.

2) Mean Absolute Percentage Error (MAPE):

$$
M A P E=\frac{1}{n} \sum_{t=1}^{n}\left|\frac{A_{t}-F_{t}}{A_{t}}\right|,
$$

where $A_{t}$ is the actual value at the time to $t, F_{t}$ is the predicted value at time to $t$, and $n$ is lots of data. MAPE value is used to analyze process performance prediction as shown in Table 1 [6]. MAPE was also often useful for purposes of reporting, because it was expressed in generic percentage terms that would be understandable to a wide range of users.
Table 1. MAPE value for prediction evaluation.

\begin{tabular}{cc}
\hline \hline MAPE Value & Prediction Accuracy \\
\hline MAPE $\leq 10 \%$ & High \\
$10 \%<$ MAPE $\leq 20 \%$ & Good \\
$20 \%<$ MAPE $\leq 50 \%$ & Reasonable \\
MAPE $>50 \%$ & Low \\
\hline \hline
\end{tabular}

\section{RESUlt AND DISCUSSION}

The initial stage of testing is predicting sales quantity of each product per month with SES method using Equation (1) with parameter $\alpha=0.1, \alpha=0.3, \alpha=0.5, \alpha=0.7$, and $\alpha=0.9$.

The next stage is to calculate the difference between the predicted sales quantity with actual data to obtain the values of MAE and MAPE using Equations (2) and (3). In other words, the prediction results of the sales quantity of each pharmaceutical product for the following month compared to the actual data of the sales quantity of each product in the next month.

The final stage is to calculate the average prediction error of the values of MAE and MAPE, in order to obtain the calculation results as shown in Fig. 2 and Fig. 3.

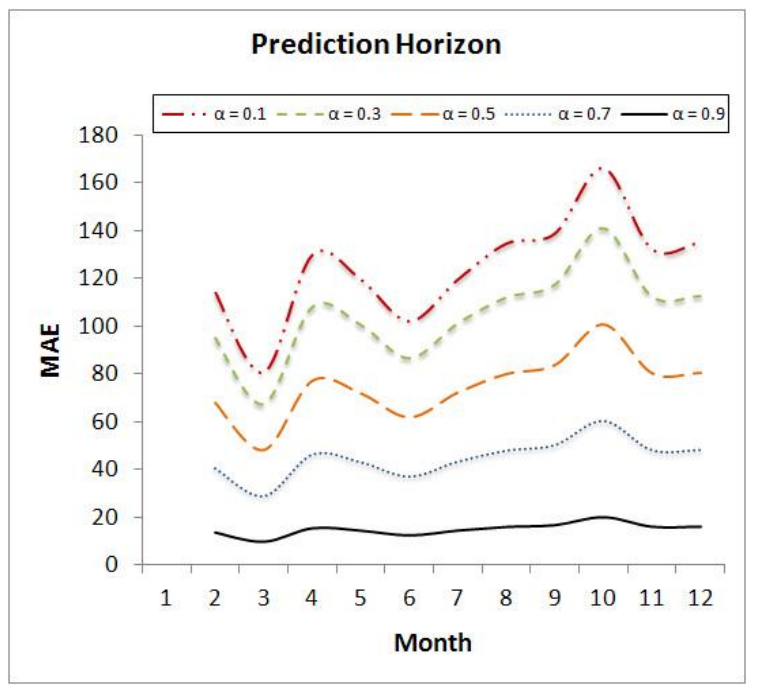

Fig. 2. The result of the calculation of average prediction error (MAE).

Table 2 presents the average prediction error for each pharmaceutical product sales, for each smoothing parameter $\alpha$ used in this study.

The error results in Fig. 2, Fig. 3 and Table 2 show clearly that $\alpha=0.9$ was the most accurate parameter for the sales prediction of pharmaceutical products for one year in the prediction horizon.

Fig. 2, Fig. 3 and Table 2 show that the calculation results predicted sales quantity of pharmaceutical products using SES method with $\alpha=0.9$ produce MAE is 14.97 and MAPE as low as $1.056 \%$, so that based on the evaluation criteria of MAPE value in Table 1, the category of prediction accuracy of sales quantity of pharmaceutical products in a pharmacy in Palembang city is high, because the MAPE value $\leq 10 \%$. 


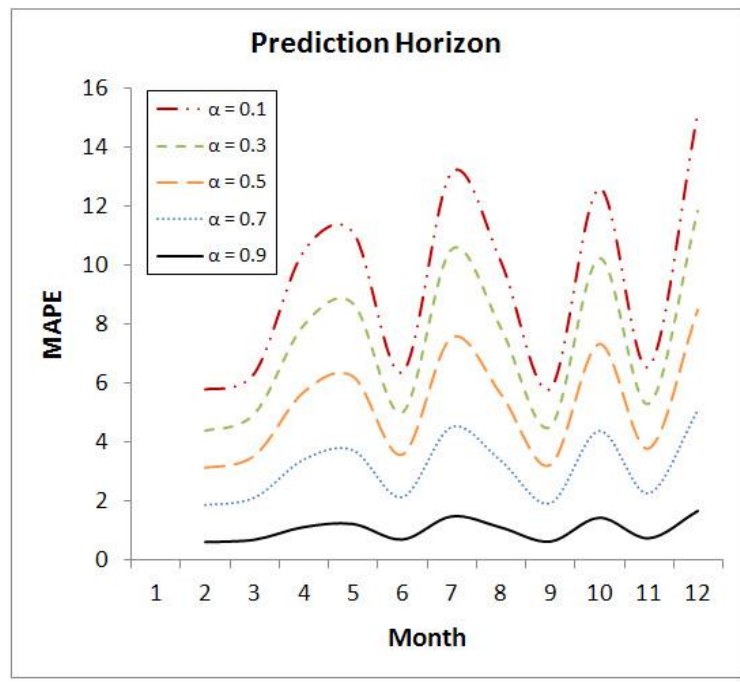

Fig. 3. The result of the calculation of average prediction error (MAPE).

Table 2. The average prediction error of each pharmaceutical product sales.

\begin{tabular}{crrrrr}
\hline \hline \multirow{2}{*}{$\begin{array}{c}\text { Standard } \\
\text { Measurements }\end{array}$} & \multicolumn{5}{c}{ Smoothing Parameter } \\
\cline { 2 - 6 } & $\alpha=0.1$ & $\alpha=0.3$ & $\alpha=0.5$ & $\alpha=0.7$ & $\alpha=0.9$ \\
\hline MAE & 124.81 & 104.78 & 74.84 & 44.91 & 14.97 \\
MAPE & 9.41 & 7.39 & 5.28 & 3.17 & 1.06 \\
\hline \hline
\end{tabular}

If taken randomly, one product (Amoxicillin 500 tab) of 6,877 products as an example, then Fig. 4 is a comparison

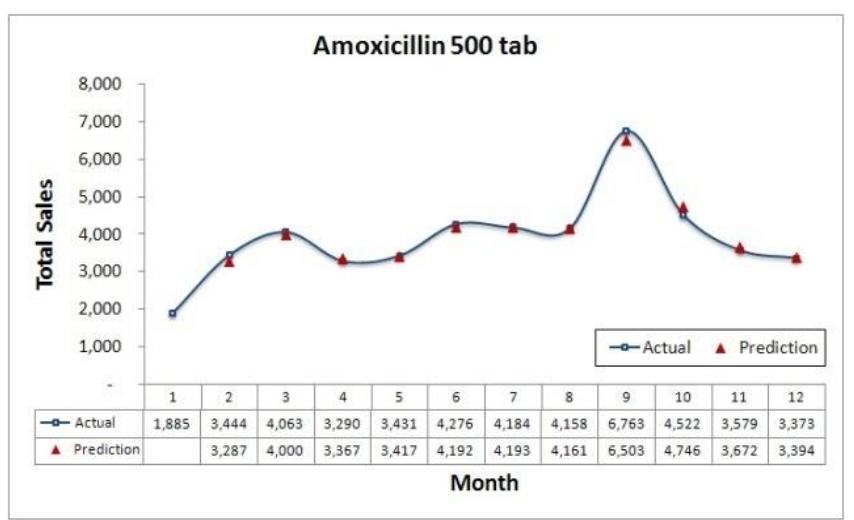

graph between the actual data to the predicted sales data.

Fig. 4. The comparison graph between actual data to sales prediction data for one product (Amoxicillin $500 \mathrm{tab}$ ).

The results of this evaluation indicate that the SES method can contribute to the development of sales prediction system or inventory system in pharmacy that is still very [3].

\section{CONCLUSION}

These results indicated that the accuracy of the predicted sales quantity of pharmaceutical products using the Single Exponential Smoothing method is high (MAPE $=1.06 \%$ ). This study has also shown that the SES method with the smoothing parameter $\alpha=0.9$ is the best parameter $\alpha$ to predict the sales quantity of each product by a percentage of average accuracy is higher than the others parameter, so the SES method can also be used as a reference for a decision support system to optimize product purchase.

Further research can apply a variety of other prediction methods such other time series model or machine learning model and so on in order to obtain the most accurate method to predict sales multiple products with a pattern of data as in this study.

\section{REFERENCES}

[1] R. Gustriansyah, D. I. Sensuse, and A. Ramadhan, "A sales prediction model adopted the recency-frequency-monetary concept," Indones. J. Electr. Eng. Comput. Sci., vol. 6, no. 3, pp. 711-720, 2017.

[2] R. Gustriansyah, D. I. Sensuse, and A. Ramadhan, "Decision support system for inventory management in pharmacy using fuzzy analytic hierarchy process and sequential pattern analysis approach," in CONMEDIA 2015 - International Conference on New Media 2015, 2016.

[3] P. Kelle, J. Woosley, and H. Schneider, "Pharmaceutical supply chain specifics and inventory solutions for a hospital case," Oper. Res. Heal. Care, vol. 1, no. 2-3, pp. 54-63, 2012.

[4] S. Dwivedi, A. Kumar, and P. Kothiya, "Inventory Management: A Tool of Identifying Items That Need Greater Attention for Control," Pharma Innov., vol. 1, no. 7, pp. 125$29,2012$.

[5] D. Nadyatama, Q. Aini, and M. C. Utami, "Analysis of commodity inventory with exponential smoothing and silver meal algorithm (Case study)," in 2016 4th International Conference on Cyber and IT Service Management, 2016, pp. 16.

[6] R. Anggrainingsih, Aprianto, G. Romadhon, and S. W. Sihwi, "Time Series Forecasting Using Exponential Smoothing To Predict The Number of Website Visitor of Sebelas Maret University," in 2nd Int. Conference on Information Technology, Computer and Electrical Engineering (ICITACEE), 2015, pp. 1-6.

[7] Y. Ding, Q. Wen, and B. Shen, "Prediction on Diesel Price in China with an Exponential Smoothing Method," in 2014 Seventh International Joint Conference on Computational Sciences and Optimization, 2014, pp. 593-597.

[8] A. C. Adamuthe, R. A. Gage, and G. T. Thampi, "Forecasting Cloud Computing using Double Exponential Smoothing Methods," in International Conference on Advanced Computing and Communication Systems (ICACCS-2015), 2015, pp. 1-5.

[9] A. A. Hidayat, Z. Arief, and D. C. Happyanto, "Mobile Application With Simple Moving Average Filtering For Monitoring Finger Muscles Therapy Of Post-Stroke People," in International Electronics Symposium (IES), 2015, pp. 1-6.

[10] T. Fehlmann and E. Kranich, "Exponentially Weighted Moving Average (EWMA) Prediction in the Software Development Process," in 2014 Joint Conference of the International Workshop on Software Measurement and the International Conference on Software Process and Product Measurement, 2014, pp. 263-270.

[11] R. Nau, "Averaging and Exponential Smoothing Models," $2017 . \quad$ [Online]. Available: http://people.duke.edu/ rnau/411avg.htm. [Accessed: 20-Sep2017].

[12] K. Fu, W. Chen, L.-C. Hung, and S. Peng, "An ABC Analysis Model for the Multiple Products Inventory Control ...- A Case Study of Company X," in the Asia Pacific Industrial Engineering \& Management Systems Conference, 2012, pp. 495-503. 